\title{
Gray Platelet Syndrome
}

\section{Demonstration of Alpha Granule Membranes That Can Fuse with the Cell Surface}

\author{
Jean-Philippe Rosa, „ James N. George,“ Dorothy F. Bainton, ${ }^{\star}$ Alan T. Nurden, Jacques P. Caen, ${ }^{5}$ and Rodger P. McEver \\ ${ }^{*}$ Departments of Medicine and Cellular and Structural Biology, University of Texas Health Science Center, San Antonio, \\ Texas 78284-7880; 'Department of Pathology, University of California School of Medicine, San Francisco, California 94143; \\ ${ }^{\S}$ Unité 150 INSERM, Hôpital Lariboisiere, Paris, France
}

\begin{abstract}
Platelets from patients with the gray platelet syndrome have decreased recognizable alpha granules and are markedly deficient in some alpha-granule secretory proteins. Using immunocytochemical techniques with antibodies to an alpha-granule membrane protein, GMP-140, we identified the membranes of intracellular vesicles in gray platelets as alpha-granule membranes. Gray platelets contained normal amounts of GMP-140 as measured by electroimmunoassay. The activation of gray platelets with thrombin caused GMP-140 to be redistributed to the plasma membrane surface, as in normal platelets. In agreement with previous studies, an endogenously synthesized secretory protein, platelet factor 4 , was undetectable in gray platelets. However, the alpha-granule proteins albumin and IgG, which are thought to be derived from endocytosis of plasma proteins into megakaryocytes, were present in substantial quantities and were secreted efficiently from gray platelets. Therefore, the fundamental defect in the gray platelet syndrome may be in the targeting of endogenously synthesized secretory proteins to developing alpha granules in megakaryocytes.
\end{abstract}

\section{Introduction}

The gray platelet syndrome is a rare congenital bleeding disorder first described by Raccuglia (1). Gray platelets are markedly deficient in morphologically recognizable alpha granules (2) and in the alpha-granule secretory proteins platelet factor 4, beta-thromboglobulin, fibrinogen, von Willebrand factor, platelet-derived growth factor, fibronectin, and thrombospondin (3-7). However, ultrastructural and biochemical studies have indicated that lysosomes, peroxisomes, dense bodies, and their contents are normal in gray platelets $(2,3,5,8)$.

The cause of the defect accounting for the alpha-granule abnormality in gray platelets is unknown. Many gray platelets are highly vacuolated $(2,5)$, and immunocytochemical studies

Address reprint requests to Dr. McEver, Cardiovascular Biology Program, Oklahoma Medical Research Foundation, 825 N.E. 13th Street, Oklahoma City, OK 73104.

A preliminary report of this study was presented at the meeting of the Council on Thrombosis of the American Heart Association, 19 November 1986, Dallas, TX, and published in abstract form. (1986. Circulation. 74:II-423.)

Received for publication 7 February 1987 and in revised form 27 April 1987.

J. Clin. Invest.

(c) The American Society for Clinical Investigation, Inc.

0021-9738/87/10/1138/09 \$2.00

Volume 80, October 1987, 1138-1146 have shown that some of the vesicles contain small quantities of the alpha-granule proteins fibrinogen and von Willebrand factor (9). Immunocytochemical analysis has also documented the presence of fibrinogen in the surface-connected canalicular system of gray platelets and von Willebrand factor in the Golgi region and some small vesicles of megakaryocytes from patients with the gray platelet syndrome (9). Although these observations did not provide direct evidence for alpha-granule membranes in gray platelets, they led to the hypothesis that the alpha-granule abnormality arises from a defect in the mechanisms for transferring proteins into developing alpha granules, rather than defective synthesis of alpha-granule membranes (2, $8,9)$. It was proposed that instead of being transferred to alpha granules, these proteins were constitutively secreted from megakaryocytes.

It has been thought that most, if not all, alpha-granule secretory proteins are synthesized by megakaryocytes, and there is direct evidence that some of the proteins are synthesized endogenously (10-14). However, we have recently shown that a plasma protein can be endocytosed by megakaryocytes and incorporated into alpha granules (15). Major plasma proteins such as albumin and IgG may be routed into platelet alpha granules by this endocytotic pathway $(16,17)$, since the concentrations of these proteins in the platelet are directly related to their concentrations in plasma (18). The concentration and disposition of presumably exogenously acquired proteins in gray platelets are less well understood than the concentration and disposition of the endogenously synthesized alpha-granule proteins. The platelet albumin concentration in one patient with the gray platelet syndrome was reported to be approximately half the normal value (4), but albumin secretion was not studied in this patient.

We have previously described a monoclonal antibody, designated S12, which reacts with a platelet membrane protein of 140,000 relative molecular mass $\left(M_{\mathrm{r}}\right)$ that is localized to the membranes of alpha granules in unstimulated platelets, but is redistributed to the plasma membrane of activated platelets during secretion (19-21). The protein has been named GMP-140, ${ }^{1}$ to indicate that it is a granule membrane protein. Similar findings have been described by Furie and co-workers $(22,23)$. GMP-140 appears to be localized to alpha granules in megakaryocytes and is presumed to be synthesized by these cells $(24,25)$. In this study, using antibodies to GMP-140 as a marker, we show that many vesicles in gray platelets contain alpha-granule membrane proteins and that these vesicles fuse with the plasma membrane after the cells have been activated with thrombin, resulting in the normal distribution of GMP-140 over the platelet surface. We also show by enzyme-

1. Abbreviation used in this paper: GMP-140, alpha-granule membrane protein. 
linked immunoassay (ELISA) and electroimmunoassay that gray platelets contain substantial quantities of IgG and albumin and that these proteins are secreted appropriately from activated cells. These findings suggest that the alpha-granule abnormalities in the gray platelet syndrome may be due to abnormal targeting of endogenously synthesized secretory proteins to developing alpha granules in megakaryocytes.

\section{Methods}

Patients. Platelets from two unrelated patients with gray platelet syndrome were studied. H.B. has been the subject of several reports $(4,5$, 8 , 9). A preliminary report on S.S. has been published (26). Blood samples were taken from the patients and from normal volunteers with informed consent. Platelets from H.B. were used in immunocytochemical studies and for analysis by crossed immunoelectrophoresis. All other studies were performed on platelets from S.S.

Antibodies. Two monoclonal antibodies were used: S12, which recognizes the platelet alpha-granule membrane protein GMP-140 (19, 20); and Tab, which recognizes platelet membrane glycoprotein IIb $(27,28)$. Rabbit polyclonal antibodies to platelet factor 4 (29) were a gift from Dr. Shirley P. Levine (University of Texas Health Science Center at San Antonio). Rabbit polyclonal antibodies to GMP-140, glycoprotein IIb, and glycoprotein IIIa were prepared as described previously $(20,30)$. A monoclonal antibody to human albumin was obtained from Accurate Chemical and Scientific Corp., Westbury, NY. Goat affinity-purified polyclonal antibodies to human albumin and IgG were obtained from Cappel Laboratories, Malvern, PA. Biotinylated antibodies and avidin D-biotinylated horseradish peroxidase were obtained from Vector Laboratories, Burlingame, CA.

Platelet isolation. In one instance, blood from patient H.B. was drawn immediately into fixative and the platelets were isolated as previously described for subsequent immunocytochemistry (20). Otherwise, platelets were isolated by published procedures (31), then resuspended at $10^{8}$ cells $/ \mathrm{ml}$ in Tyrode's buffer $(138 \mathrm{mM} \mathrm{NaCl}, 29 \mathrm{mM} \mathrm{KCl}$, $12 \mathrm{mM} \mathrm{NaHCO}_{3}, 0.4 \mathrm{mM} \mathrm{NaHPO}_{4}, 0.1 \%$ glucose, and $0.35 \%$ bovine serum albumin, BSA), pH 7.4, containing 5 mM EDTA. The platelets were incubated with control buffer or with $1.0 \mathrm{U} / \mathrm{ml}$ of alpha-thrombin $(2,600 \mathrm{U} / \mathrm{mg}$, a gift from Dr. John W. Fenton II, Albany, NY) for 10 min at $37^{\circ} \mathrm{C}$. Thrombin was inactivated by adding $2 \mathrm{U} / \mathrm{ml}$ of hirudin for $5 \mathrm{~min}$. The cells were then processed for binding studies and immunocytochemistry, or lysed for immunoelectrophoresis, Western blots, or ELISA as described below.

Platelet binding studies. The binding of ${ }^{125} \mathrm{I}$-labeled $\mathrm{S} 12$ or Tab IgG to unstimulated or stimulated platelets was performed as previously described (31), except that the platelets were not fixed and the binding studies were performed immediately after the platelets had been isolated.

Western blotting. A portion of the unstimulated platelets was solubilized in $2 \%$ sodium dodecyl sulfate (SDS). Then $25-\mu \mathrm{g}$ samples were electrophoresed on 7\% SDS polyacrylamide gels, transferred to nitrocellulose paper, and probed with polyclonal or monoclonal antibodies to GMP-140 and glycoprotein IIIa as previously described (20), except that the BLOTTO method was used for washing (32). Molecular weights were estimated by simultaneous electrophoresis of a prestained protein mixture containing myosin, phorphorylase B, BSA, and ovalbumin (Bethesda Research Laboratories, Gaithersburg, MD).

Electroimmunoassay. Rocket immunoelectrophoresis was performed as previously described (33), with slight modifications. Platelet samples originally prepared for Western blotting were analyzed. Before electrophoresis, samples were diluted in four volumes of $38 \mathrm{mM}$ Tris, $100 \mathrm{mM}$ glycine, $\mathrm{pH} 8.7$, containing $1 \%$ Triton X-100. 10- $\mu$ l aliquots containing $20 \mu \mathrm{g}$ of platelet protein were electrophoresed $(10 \mathrm{~V} / \mathrm{cm}, 4$ h) in agarose containing $7.5 \mu \mathrm{l} / \mathrm{cm}^{2}$ of rabbit antisera to platelet factor 4 or $3.0 \mu \mathrm{g} / \mathrm{cm}^{2}$ of goat affinity-purified antibodies to human albumin. For quantitation of GMP-140, ${ }^{125} \mathrm{I}-\mathrm{S} 12\left(1.9 \mu \mathrm{g}, 1.2 \times 10^{6} \mathrm{cpm}\right)$ was incorporated into an agarose gel containing $450 \mu \mathrm{g} / \mathrm{cm}^{2}$ of rabbit IgG antibodies to human platelet proteins $(28,33)$. Plates were then washed, stained with Coomassie Blue, dried, and, when indicated, subjected to autoradiography. Crossed immunoelectrophoresis was performed as described previously (19).

Immunocytochemistry. Immediately fixed, washed, or thrombinstimulated platelets were fixed in $8 \%$ paraformaldehyde in $0.1 \mathrm{M}$ PIPES buffer (pH 7.2) and were washed in the same buffer containing $10 \%$ (wt/vol) sucrose $(20,34)$. They were infiltrated for $30 \mathrm{~min}$ with 2.3 $M$ sucrose, embedded in the sucrose solution, frozen, and stored in liquid nitrogen. The frozen thin-section techniques described by Tokuyasu (35) were used, with the modifications described by Griffiths et al. (36). When sections were incubated with polyclonal antibodies, the probe was $5 \mathrm{~nm}$ colloidal gold conjugated with protein A-5; for sections incubated with monoclonal antibody, the probe was $5 \mathrm{~nm}$ colloidal gold conjugated with goat anti-mouse IgG (Janssen Pharmaceuticals, Beerse, Belgium). Control measures for all procedures included the substitution of buffer, preimmune rabbit serum, or purified mouse IgG for specific primary antibody.

ELISA. Platelets were prepared and assayed for IgG and albumin by an antibody-capture ELISA system as described previously (16). For the albumin assay, affinity-purified goat anti-human albumin was used to coat the wells, and the same antibody was biotinylated for use as the detection reagent.

Protein determination. Proteins were determined by the method of Markwell (37).

\section{Results}

To determine the content and subcellular location of GMP-140 in gray platelets, we performed direct platelet-binding studies with ${ }^{125} \mathrm{I}-\mathrm{S} 12 \mathrm{IgG}$. As shown in Fig. $1 A$, very few ${ }^{125} \mathrm{I}-\mathrm{S} 12$ molecules bound to unstimulated gray platelets or normal platelets. However, thrombin-stimulated gray platelets bound $\sim 6,000$ S1 2 molecules, a number comparable to that bound by stimulated normal platelets. These binding values are similar to our previously reported normal values $(19,31)$. As a control, we measured binding to a protein located predominantly in the plasma membrane by using Tab, a monoclonal antibody that recognizes the IIb subunit of the glycoprotein IIb-IIIa complex, the platelet fibrinogen receptor (27, 28 ). ${ }^{125} \mathrm{I}-\mathrm{Tab}$ bound normally (Fig. $1 \mathrm{~B}$ ) to gray and normal platelets. The increased binding of Tab to stimulated platelets probably reflects increased accessibility of the IgG to the surface connected canalicular system, which widens after platelet activation $(31,34,38)$.

The expression of S12-binding sites on thrombin-stimulated gray platelets suggested that gray platelets contained alpha-granule membranes that could fuse normally with the plasma membrane after platelet activation. To determine whether the membranes of empty vacuoles previously observed in gray platelets $(2,5)$ were alpha-granule membranes, we incubated frozen thin sections of normal and gray platelets with polyclonal antibodies to GMP-140, followed by protein A conjugated to colloidal gold. Immunogold label was readily seen along the alpha-granule membranes of normal platelets (Fig. 2; and reference 20). In gray platelets gold label was seen mainly along the membranes of numerous vacuoles of variable size (Fig. 3) and in occasional electron-dense alpha granules (inset, Fig. 3). When gray platelets were stimulated with thrombin, the immunogold label was redistributed almost entirely to the surface-connected canalicular system and plasma membrane (Fig. 4) in a manner comparable to that seen in normal stimulated platelets (20). 

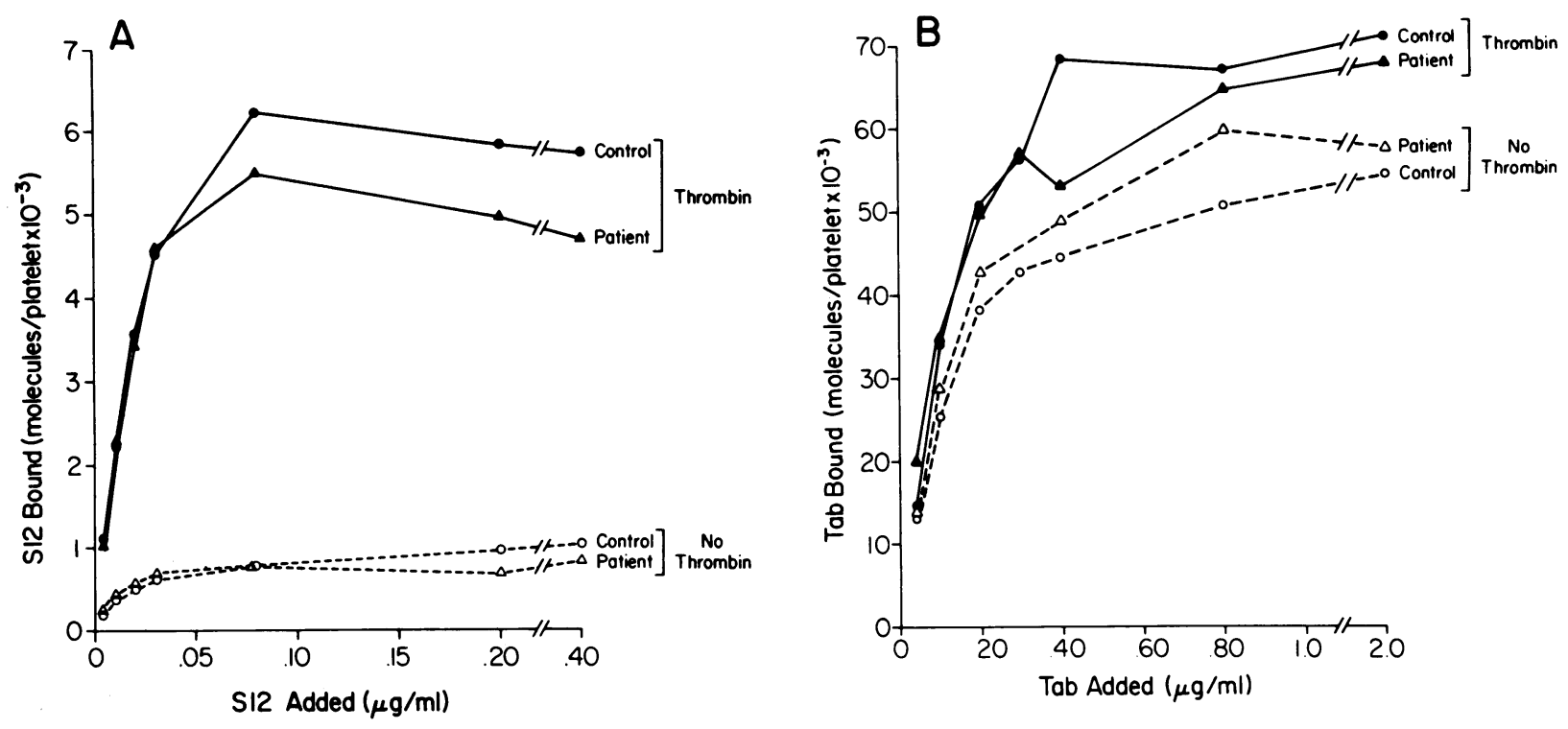

Figure 1. Specific binding of ${ }^{125} \mathrm{I}$-labeled monoclonal antibodies to normal and gray platelets. Platelets were incubated with or without thrombin before the measurement of antibody binding as described in Methods. $(A)$ Binding of S12, a monoclonal antibody that recognizes the platelet alpha-granule membrane protein GMP-140. (B) Binding of Tab, a monoclonal antibody that recognizes the plasma membrane glycoprotein IIb.

Electroimmunoassay of platelet lysates also demonstrated that normal and gray platelets contained comparable quantities of immunoreactive GMP-140 (Fig. 5). Platelet samples from patients H.B. and S.S. contained identical amounts of GMP-140 when analyzed by crossed immunoelectrophoresis (not shown). Western blot analysis of nonreduced gray platelet lysates probed with polyclonal antibodies to GMP-140 (Fig. 6) or S12 (not shown) indicated that the protein comigrated with the GMP-140 in normal platelets. Gray-platelet GMP-140 electrophoresed under reducing conditions also comigrated with the protein in normal platelets (not shown).

Electroimmunoassay of platelet proteins from patient S.S. demonstrated that the platelet albumin was $58 \%$ of the mean value of a series of normal platelet samples, whereas platelet

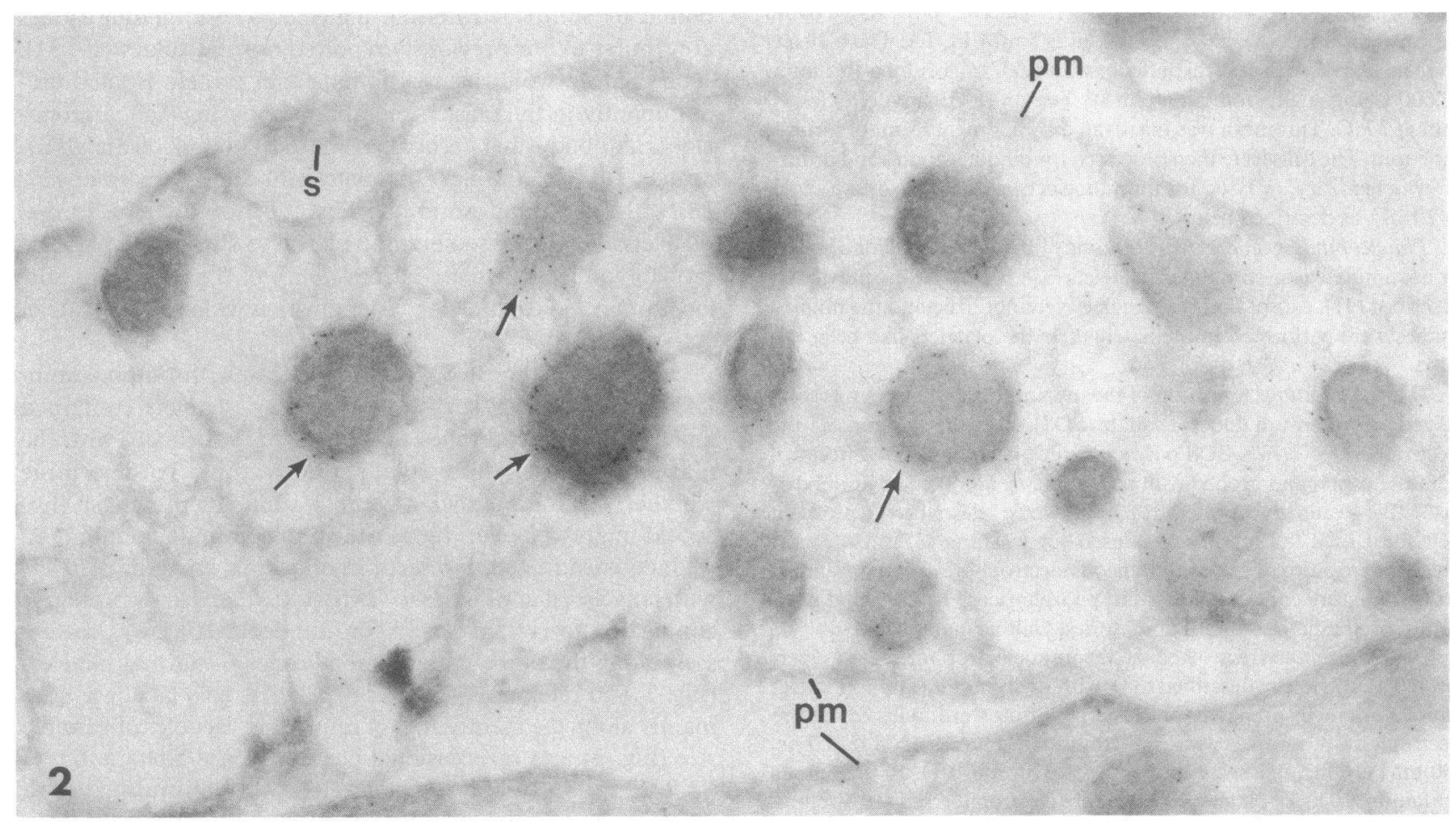

Figure 2. Frozen thin section of unstimulated normal platelets exposed to polyclonal antibodies to GMP-140, followed by protein A-gold 5 conjugate. Note the extensive label along alpha-granule membranes (arrows). Granule membrane labeling is variable, however, with a mean of 9 grains per granule (range 2-24). Labeling of the plasma membrane $(\mathrm{pm})$ and surface-connected canalicular system $(s)$ is insignificant. $\times 62,000$. 


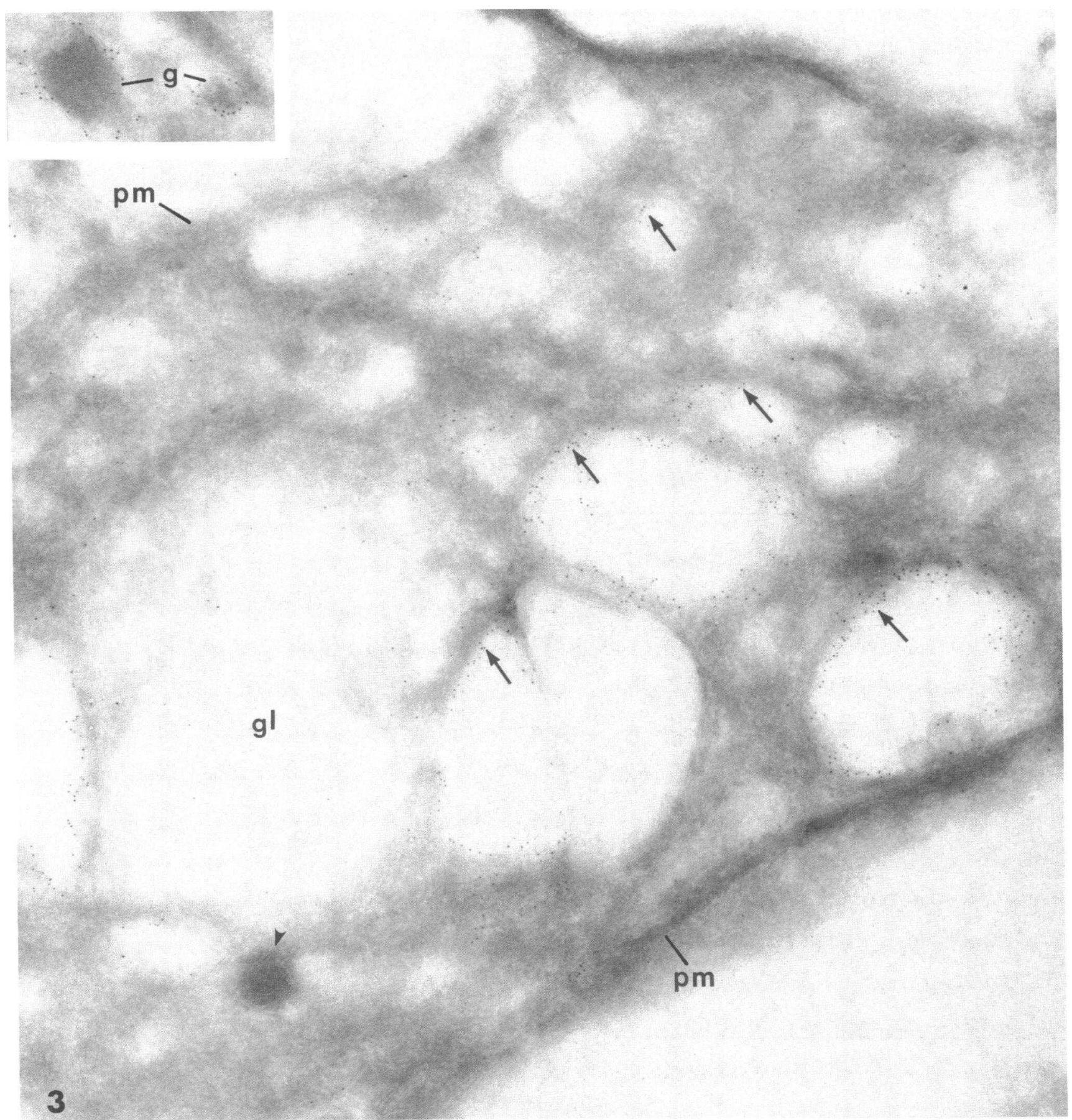

Figure 3. Frozen thin section of unstimulated gray platelets exposed to antibodies to GMP-140, followed by immunogold conjugate. Occasional small, moderately dense alpha granules are seen (inset), which label with immunogold. The platelet is filled mainly with small and large vacuoles whose membranes are labeled for GMP-140

factor 4 was undetectable (Fig. 7). It was previously shown that the platelet albumin level in patient H.B. was $47 \%$ of the normal value (4). Using an ELISA method, we found that platelets from patient S.S. contained significant quantities of $\mathrm{IgG}$ as well as albumin (Table I). Furthermore, as in normal platelets, most of the albumin and IgG was secreted from gray platelets activated with thrombin.

Since both albumin and IgG were efficiently secreted from activated gray platelets, it seemed likely that these proteins (arrows). Note that not all vacuoles are labeled: these probably represent the surface-connected canalicular system. Small organelles (arrowhead) with no GMP-140 may be lysosomes or peroxisomes. pm, plasma membrane; $g l$, glycogen. $\times 58,000$. Inset $\times 65,000$.

were present in alpha-granulelike structures. To determine the subcellular localization of albumin, we incubated frozen thin sections of gray platelets with a monoclonal antibody to albumin, followed by the GAM-gold conjugate. The immunogold probe was localized to small, electron-dense granules and to a lesser extent to large vacuolar structures (Fig. 8). Gold labeling was minimal in the cell cytoplasm. Since the membranes of most intracellular vacuoles as well as the rare electron-dense granules in gray platelets contained GMP-140 (Fig. 3), this 


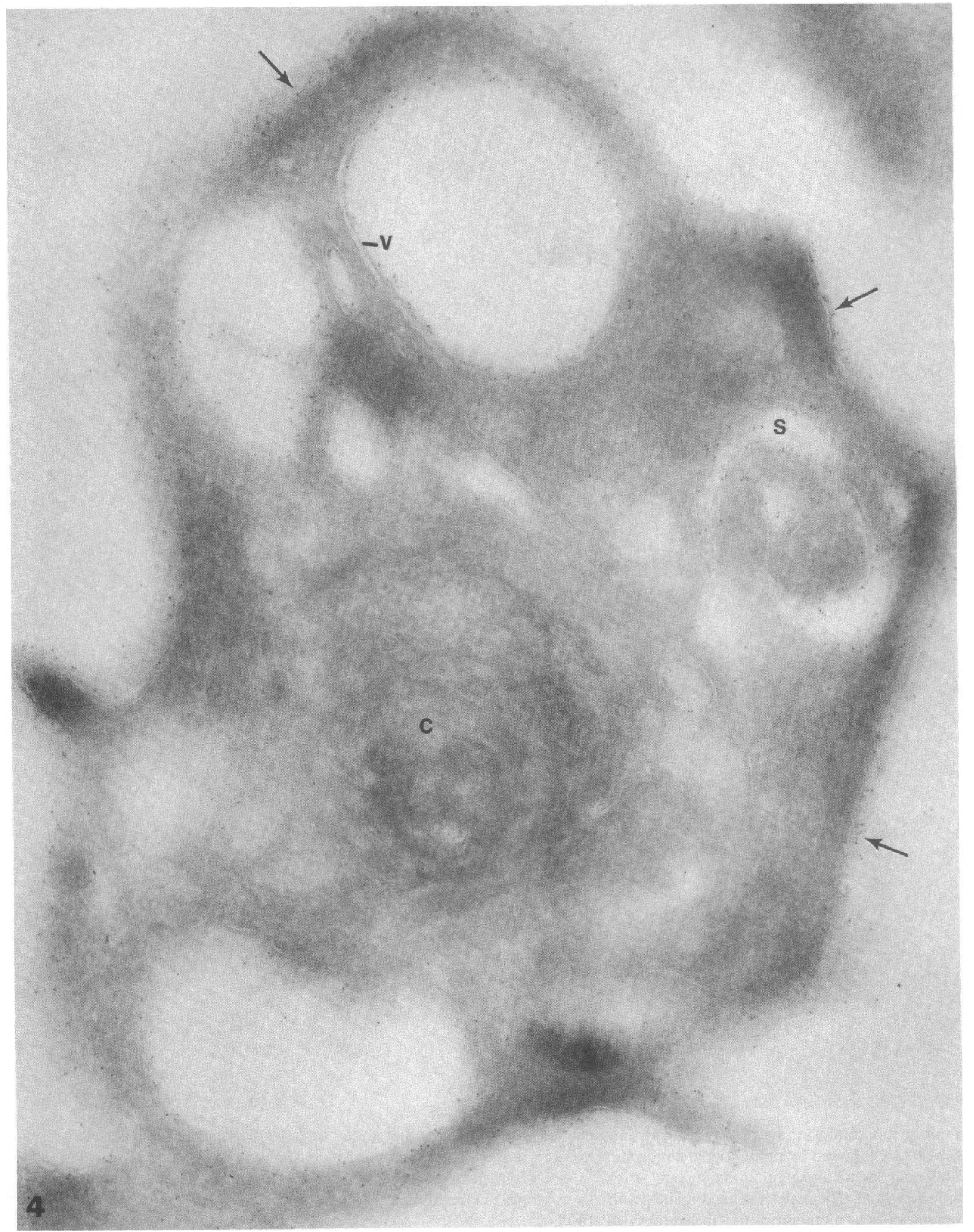

Figure 4. Frozen thin section of thrombin-stimulated gray platelets exposed to antibodies to GMP-140, followed by immunogold conjugate. Shape change has occurred and the center $(c)$ of the cell is now occupied by a dense mass of cytoskeletal elements. Note the exten-

finding suggests that most of the albumin (and probably IgG) in these cells is localized in alpha-granulelike vesicles. Most of these vesicles appeared nearly empty, but some contained enough secretory protein to appear electron-dense. sive label along the plasma membrane (arrows) and the membranes of vacuoles $(v)$ that may be in continuity with the surface-connected canalicular system $(s) . \times 58,000$.

\section{Discussion}

Our results indicate that platelets from patients with the gray platelet syndrome contain normal quantities of the alpha- 


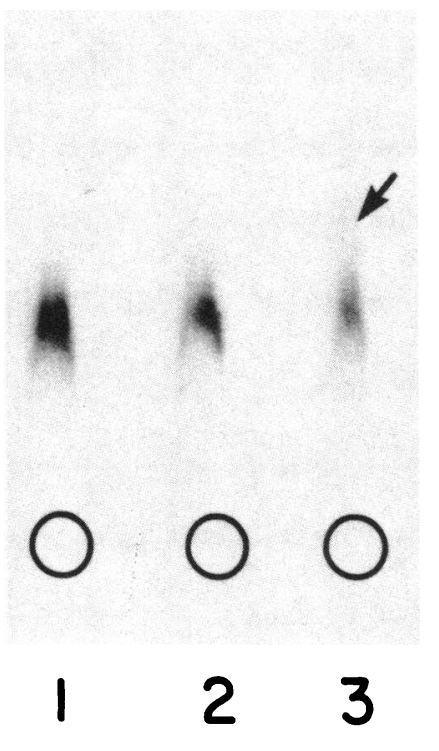

Figure 5. Quantitation of GMP-140 in normal and gray platelets by electroimmunoassay. 20- $\mu \mathrm{g}$ samples of platelet lysates were electrophoresed in agarose containing $450 \mu \mathrm{g} / \mathrm{cm}^{2}$ of polyclonal antibodies to human platelet proteins and $1.2 \times 10^{6} \mathrm{cpm}$ of ${ }^{125} \mathrm{I}-\mathrm{S} 12$, the monoclonal antibody to GMP-140. The plate was then washed, dried, and subjected to autoradiography. Lanes 1 and 2, normal platelets. Lane 3 , gray platelets.

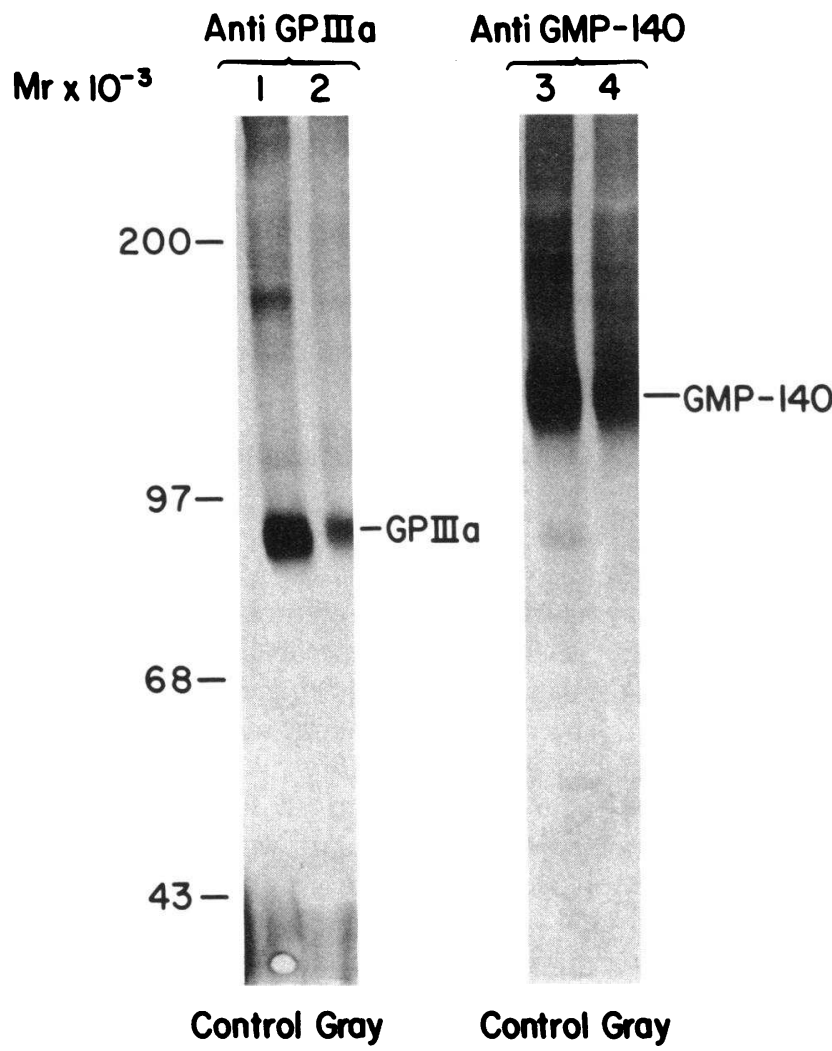

Figure 6. Western blot analysis of normal and gray-platelet proteins probed with antibodies to GMP-140. 25- $\mu \mathrm{g}$ samples of platelet protein were electrophoresed under nonreducing conditions in a 7\% SDS-polyacrylamide gel, transferred to nitrocellulose paper, and probed with rabbit polyclonal antibodies to GMP-140 (lanes 3 and 4). Lanes 1 and 2 were incubated with antibodies to plasma-membrane glycoprotein IIIa as a positive control to insure loading of adequate protein on the gel for analysis. Bound antibody was detected with an ELISA system. Lanes 1 and 3, normal platelets. Lanes 2 and 4, gray platelets. The staining seen in lanes 3 and 4 above the GMP-140 band reflects antibody reactivity with GMP-140 that occasionally forms mixed disulfide bonds with other proteins when electrophoresed under nonreducing conditions. The staining is not seen with more dilute antibody or with blots performed under reducing conditions.

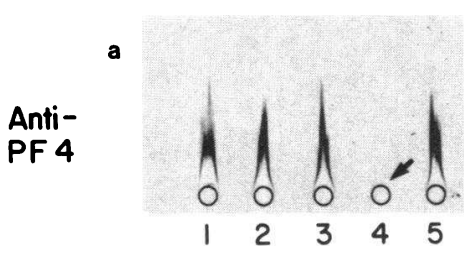

Figure 7. Quantitation of albumin and platelet factor 4 in normal and gray platelets by electroimmunoassay. Experimental conditions were as in Fig. 5 except that the agarose contained polyclonal antibodies to platelet factor 4

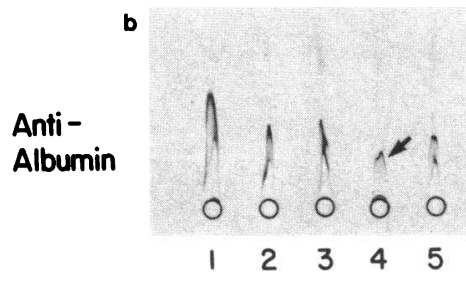

$(a)$ or to albumin $(b)$. After electrophoresis, the plates were washed, stained with Coomassie Blue, and dried. Lanes 4 (arrows) correspond to gray platelets. Lanes $1-3$, and 5 are normal platelets.

granule membrane protein GMP-140 in vesicle membranes and that the protein is redistributed normally to the plasma membrane surface when the platelets are stimulated with thrombin. These observations suggest that alpha-granule membranes are synthesized normally in megakaryocytes from these patients and retain the capacity to fuse with the plasma membrane during platelet secretion.

Our data also indicate that gray platelets contain substantial quantities of albumin and IgG in alpha-granulelike vesicles. These proteins are as efficiently secreted from thrombinstimulated gray platelets as they are from normal cells $(16,18)$. We have recently shown that guinea pig megakaryocytes can endocytose an intravenously injected marker protein, horseradish peroxidase, and incorporate it into developing alpha granules (15). Platelets with peroxidase in their alpha granules subsequently appear in the circulation and, when stimulated, secrete the peroxidase. This observation suggests that endocytosis may be a common mechanism for incorporation of plasma proteins into alpha granules. Endocytosis is a likely mechanism for the delivery of albumin and IgG to alpha granules since: $(a)$ in platelets, both proteins are found almost exclusively within alpha granules (16-18); (b) the plasma concentration of both proteins is high; and $(c)$ the platelet content

Table I. Content of Albumin and IgG in Normal and Gray Platelets

\begin{tabular}{llllll}
\hline & Albumin & & & IgG & \\
\cline { 2 - 3 } \cline { 5 - 6 } & $\begin{array}{l}\text { Normal } \\
\text { platelets }\end{array}$ & $\begin{array}{l}\text { Gray } \\
\text { platelets }\end{array}$ & & $\begin{array}{l}\text { Normal } \\
\text { platelets }\end{array}$ & $\begin{array}{l}\text { Gray } \\
\text { platelets }\end{array}$ \\
\hline $\begin{array}{c}\text { Protein content, } \\
n g / 10^{6} \text { platelets }\end{array}$ & 19.2 & 6.5 & & 5.3 & 3.3 \\
$\begin{array}{c}\text { Thrombin-induced } \\
\text { secretion }\end{array}$ & $94 \%$ & $87 \%$ & $95 \%$ & $77 \%$ \\
\hline
\end{tabular}

Normal and gray platelets were isolated, incubated with or without thrombin, and then separated by centrifugation as described in Methods. Albumin and IgG contents were determined in both supernatants and platelet lysates by an ELISA procedure. In other experiments, the pooled normal values (mean $\pm 2 S D, n=19)$ were $25.5 \pm 8.1 \mathrm{ng} / 10^{6}$ platelets for albumin and $5.2 \pm 1.5 \mathrm{ng} / 10^{6}$ platelets for IgG. The percentage of albumin and IgG secreted after thrombin activation was calculated by dividing the supernatant concentration by the combined concentration in supernatant plus platelets. 


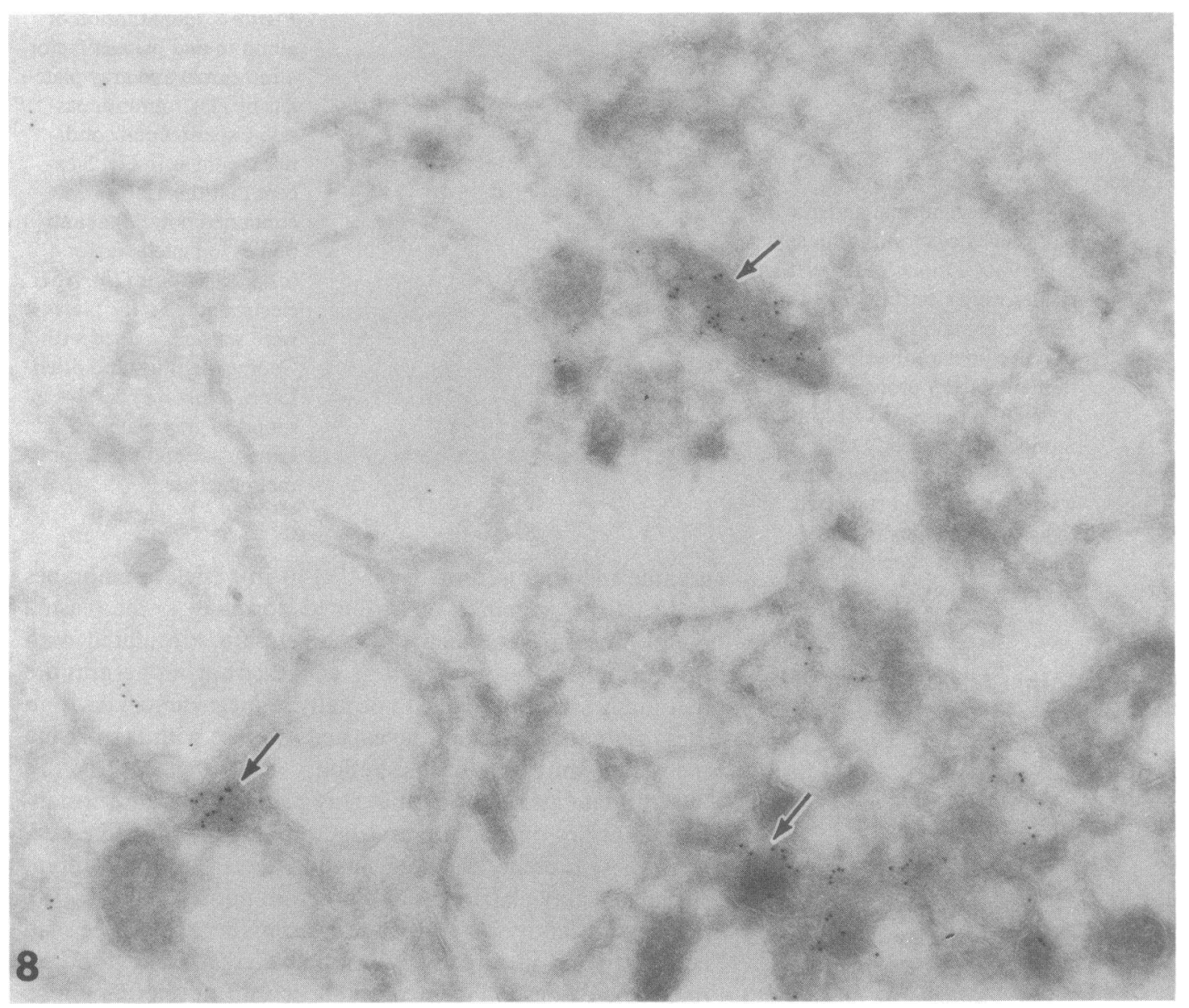

Figure 8. Frozen thin section of unstimulated gray platelets exposed to monoclonal antibodies to human albumin and then labeled with goatanti-mouse IgG-gold 5. The immunogold can be seen mainly in a few small dense granules (arrows). $\times 66,000$.

of both proteins correlates with the plasma concentration in both normal subjects and patients with dysproteinemias (18).

The concentrations of albumin and IgG are much closer to normal than are the trace levels of other alpha-granule secretory proteins found in these patients (this study; references 4, $5,29)$ and in other patients with the gray platelet syndrome $(3$, $6,7)$. The proteins found to be markedly reduced include platelet factor 4, beta thromboglobulin, thrombospondin, fibrinogen, von Willebrand factor, platelet-derived growth factor, and fibronectin. Normal megakaryocytes are known to synthesize platelet factor 4 (10), von Willebrand factor (11), fibrinogen $(12,13)$, and fibronectin (14), and are generally believed to synthesize beta thromboglobulin, thrombospondin, and platelet-derived growth factor as well. Thus, gray platelets appear to have a selective deficiency in the alphagranule secretory proteins normally derived from endogenous synthesis. Although there is no quantitative information on protein synthetic rates in megakaryocytes from these patients, several lines of evidence suggest that these cells synthesize alpha-granule proteins appropriately but then immediately release them into the bone marrow by constitutive secretion: $(a)$ the plasma concentrations of platelet factor 4 and beta thromboglobulin are normal or even increased in the patients (3, 5-7), and megakaryocytes are the only cells known to synthesize these proteins; $(b)$ immunoreactive fibrinogen has been detected along the surface-connected canalicular system of unstimulated gray platelets (9); (c) immunoreactive von Willebrand factor has been identified in the Golgi region of megakaryocytes from the patients (9); and $(d)$ increased numbers of reticulin fibers have been noted in the bone marrows of several of the patients, suggesting that megakaryocytes have inappropriately released platelet-derived growth factor $(5-8,26)$, which results in an increase of bone marrow stromal cells.

The presence of significant quantities of secretable albumin and IgG in gray platelets implies that the pathway for endocytosis of plasma proteins into alpha-granule vesicles is intact in these cells. In contrast, the alpha-granule content of endogenously synthesized secretory proteins is markedly decreased, despite apparently normal synthesis. We therefore propose that megakaryocytes in the gray platelet syndrome have a specific defect in the ability to transfer endogenously synthesized secretory proteins into alpha granules. The absence of the dense concentration of endogenously synthesized secretory proteins would account for the abnormal morphologic appearance of the granules. The defect would be analogous to the targeting abnormalities in two forms of lysosomal storage disease: I cell disease and pseudo-Hurler polydystrophy (39). Cells from patients with these diseases are unable to insert mannose-6-phosphate residues into newly synthesized lysosomal enzymes in the Golgi apparatus. The mannose-6-phosphate signal is required for normal receptor-mediated delivery of hydrolases to lysosomal vesicles. Lysosomal enzymes thus 
are constitutively secreted from affected cells. No analogous targeting signals have been identified for the routing of proteins into granules that concentrate secretory proteins and then release them to the cell exterior after the cell is stimulated. However, Kelly and colleagues have accumulated persuasive evidence that signal-receptor pathways do exist for such proteins (40).

The gray platelet syndrome may be a model for the study of targeting systems for secretory proteins. The low levels of endogenously synthesized alpha-granule proteins despite normal quantities of alpha-granule membranes and significant quantities of endocytosed alpha-granule proteins suggest distinct mechanisms for delivering soluble and membrane proteins to platelet secretory granules. The signals and receptors used for each of these pathways remain to be defined.

\section{Acknowledgments}

We are particularly grateful to Dr. Barry Coller and Dr. Mae Hultin (State University of New York at Stony Brook) for allowing us to study patient S.S., for providing laboratory space for some of the studies, and for sharing their unpublished data with us. We also thank Dr. Elisabeth Cramer for help in fixing platelets from patient H.B. for immunocytochemistry, Elaine Pickett, Sherry Saucerman, and Yvonne Jacques for technical assistance, and Dr. Geoffrey Johnston for his helpful comments on the manuscript.

Supported by grants from the National Institutes of Health (HL-34363, HL-19996, and HL-31610) and from Institut National de la Santé et de la Recherche Médicale. Dr. McEver is the recipient of a Research Career Development Award (HL-01733) from the National Institutes of Health.

\section{References}

1. Raccuglia, G. 1971. Gray platelet syndrome. A variety of qualitative platelet disorder. Am. J. Med. 51:818-828.

2. White, J. G. 1979. Ultrastructural studies of the gray platelet syndrome. Am. J. Pathol. 95:445-453.

3. Gerrard, J. M., D. R. Phillips, G. H. R. Rao, E. F. Plow, D. A. Walz, L. A. Harker, and J. G. White. 1980. Biochemical studies of two patients with the gray platelet syndrome. Selected deficiency of platelet alpha granules. J. Clin. Invest. 66:102-109.

4. Nurden, A. T., T. J. Kunicki, D. Dupuis, C. Soria, and J. P. Caen. 1982. Specific protein and glycoprotein deficiencies in platelets isolated from two patients with the gray platelet syndrome. Blood. 59:709-718.

5. Levy-Toledano, S., J. P. Caen, J. Breton-Gorius, F. Rendu, C. Cywiner-Golenzer, E. Dupuy, Y. Legrand, and J. Maclouf. 1981. Gray platelet syndrome: alpha-granule deficiency. J. Lab. Clin. Med. 98:831-848.

6. Berndt, M. C., P. A. Castaldi, S. Gordon, H. Halley, and V. J. McPherson. 1983. Morphological and biochemical confirmation of gray platelet syndrome in two siblings. Aust. N. Z. J. Med. 13:387-390.

7. Kohler, M., P. Hellstern, E. Morgenstern, C. Mueller-Eckhardt, R. Berberich, R. J. Meiser, P. Scheffler, and E. Wenzel. 1985. Gray platelet syndrome: selective alpha granule deficiency and thombocytopenia due to increased platelet turnover. Blut. 50:331-340.

8. Breton-Gorius, J., W. Vainchenker, A. Nurden, S. Levy-Toledano, and J. Caen. 1981. Defective alpha-granule production in megakaryocytes from gray platelet syndrome. Ultrastructural studies of bone marrow cells and megakaryocytes growing in culture from blood precursors. Am. J. Pathol. 102:10-19.

9. Cramer, E. M., W. Vainchenker, G. Vinci, J. Guichard, and J. Breton-Gorius. 1985. Gray platelet syndrome: immunoelectron mi- croscopic localization of fibrinogen and von Willebrand factor in platelets and megakaryocytes. Blood. 66:1309-1316.

10. Ryo, R., A. Nakeff, S. S. Huang, M. Ginsberg, and T. F. Deuel. 1983. New synthesis of a platelet-specific protein: platelet factor 4 synthesis in a megakaryocyte enriched rabbit bone marrow culture system. J. Cell Biol. 96:515-520.

11. Nachman, R., R. Levine, and E. A. Jaffe. 1977. Synthesis of factor VIII antigen by cultured guinea pig megakaryocytes. J. Clin. Invest. 60:914-921.

12. Leven, R. M., P. K. Schick, and A. Z. Budzynski. 1985. Fibrinogen biosynthesis in isolated guinea pig megakaryocytes. Blood. 65:501-504.

13. Belloc, F., P. Hourdille, P. Fialon, M. R. Boisseau, and J. Soria. 1985. Fibrinogen synthesis by megakaryocyte enriched human marrow concentrates. Thromb. Res. 38:341-351.

14. Paul, J. I., J. E. Schwarzbauer, J. W. Tamkun, and R. O. Hynes. 1986. Cell-type-specific fibronectin subunits generated by alternative splicing. J. Biol. Chem. 261:12258-12265.

15. Handagama, P. J., J. N. George, M. A. Shuman, R. P. McEver, and D. F. Bainton. 1987. Incorporation of a circulating protein into megakaryocyte and platelet granules. Proc. Natl. Acad. Sci. USA. 84:861-865.

16. George, J. N., S. Saucerman, S. P. Levine, L. K. Knierem, and D. F. Bainton. 1985. Immunoglobulin $\mathrm{G}$ is a platelet alpha granule-secreted protein. J. Clin. Invest. 76:2020-2025.

17. Sixma, J. J., A. v. d. Berg, M. Schiphorst, H. J. Geuze, and J. McDonagh. 1984. Immunocytochemical localization of albumin and Factor XIII in thin cryo sections of human blood platelets. Thromb. Haemostasis. 51:388-391.

18. George, J. N., and S. Saucerman. 1986. Platelet IgG, IgA, and albumin in ITP and in patients with abnormal serum proteins. Blood. 68(Suppl. 1):108a. (Abstr.)

19. McEver, R. P., and M. N. Martin. 1984. A monoclonal antibody to a membrane glycoprotein binds only to activated platelets. $J$. Biol. Chem. 259:9799-9804.

20. Stenberg, P. E., R. P. McEver, M. A. Shuman, Y. V. Jacques, and D. F. Bainton. 1985. A platelet alpha-granule membrane protein (GMP-140) is expressed on the plasma membrane after activation. $J$. Cell Biol. 101:880-886.

21. Isenberg, W. M., R. P. McEver, M. A. Shuman, and D. F. Bainton. 1986. Topographic distribution of a granule membrane protein (GMP-140) that is expressed on the platelet surface after activation: an immunogold-surface replica study. Blood Cells. 12:191-204.

22. Hsu-Lin, S-C., C. L. Berman, B. C. Furie, D. August, and B. Furie. 1984. A platelet membrane protein expressed during platelet activation and secretion. Studies using a monoclonal antibody specific for thrombin-activated platelets. J. Biol. Chem. 259:9121-9126.

23. Berman, C. L., E. L. Yeo, J. D. Wencel-Drake, B. C. Furie, M. H. Ginsberg, and B. Furie. 1986. A platelet alpha granule membrane protein that is associated with the plasma membrane after activation. J. Clin. Invest. 78:130-137.

24. Beckstead, J. H., P. E. Stenberg, R. P. McEver, M. A. Shuman, and D. F. Bainton. 1986. Immunohistochemical localization of membrane and alpha-granule proteins in human megakaryocytes: application to plastic-embedded bone marrow biopsy specimens. Blood. 67:285-293.

25. Stenberg, P. E., J. H. Beckstead, R. P. McEver, and J. Levin. 1986. Immunohistochemical localization of membrane and alphagranule proteins in plastic-embedded mouse bone marrow megakaryocytes and murine megakaryocyte colonies. Blood. 68:696-702.

26. Coller, B. S., M. D. Hultin, A. T. Nurden, J.-P. Rosa, and R. P. Lane. 1983. Isolated alpha-granule deficiency (gray platelet syndrome) with slight increase in bone marrow reticulin and possible glycoprotein and/or protease defect. Thromb. Haemostasis. 50:21 1a. (Abstr.)

27. McEver, R. P., N. L. Baenziger, and P. W. Majerus. 1980. Isolation and quantitation of the platelet membrane glycoprotein deficient in thrombasthenia using a monoclonal hybridoma antibody. $J$. Clin. Invest. 66:1311-1318. 
28. McEver, R. P., E. M. Bennett, and M. N. Martin. 1983. Identification of two structurally and functionally distinct sites on human platelet membrane glycoprotein IIb-IIIa using monoclonal antibodies. J. Biol. Chem. 258:5269-5275.

29. Levine, S. P., and L. S. Krentz. 1977. Development of a radioimmunoassay for human platelet factor 4. Thromb. Res. 11:673-686.

30. Bray, P. F., J.-P. Rosa, V. R. Lingappa, Y. W. Kan, R. P. McEver, and M. A. Shuman. 1986. Biogenesis of the platelet receptor for fibrinogen; evidence for separate precursors for glycoproteins IIb and IIIa. Proc. Natl. Acad. Sci. USA. 83:1480-1484.

31. George, J. N., E. B. Pickett, S. Saucerman, R. P. McEver, T. J. Kunicki, N. Kieffer, and P. J. Newman. 1986. Platelet surface glycoproteins. Studies on resting and activated platelets and platelet membrane microparticles in normal subjects, and observations in patients during adult respiratory distress syndrome and cardiac surgery. J. Clin. Invest. 78:340-348.

32. Johnson, D. A., J. W. Gautsch, J. R. Sportsman, and J. H. Elder. 1984. Improved technique utilizing nonfat dry milk for analysis of proteins and nucleic acids transferred to nitrocellulose. Gene Anal. Tech. 1:3-8.

33. George, J. N., L. L. Thoi, L. M. McManus, and T. A. Reimann.
1982. Isolation of human platelet membrane microparticles from plasma and serum. Blood. 60:834-840.

34. Stenberg, P. E., M. A. Shuman, S. P. Levine, and D. F. Bainton. 1984. Redistribution of alpha-granules and their contents in thrombin-stimulated platelets. J. Cell Biol. 98:748-760.

35. Tokuyasu, K. T. 1980. Immunochemistry on ultrathin frozen sections. Histochem. J. 12:381-403.

36. Griffiths, G., R. Brands, B. Burke, D. Louvard, and G. Warren. 1982. Viral membrane proteins acquire galactose in trans Golgi cisternae during intracellular transport. J. Cell Biol. 95:781-792.

37. Markwell, M. A. K., S. M. Haas, L. L. Bieber, and N. E. Tolbert. 1978. A modification of the Lowry procedure to simplify protein determination in membrane and lipoprotein samples. Anal. Biochem. 87:206-210.

38. Woods, V. L. Jr., L. E. Wolff, and D. M. Keller. 1986. Resting platelets contain a substantial centrally located pool of glycoprotein IIb-IIIa complex which may be accessible to some but not other extracellular proteins. J. Biol. Chem. 261:15242-15251.

39. Kornfeld, S. 1986. Trafficking of lysosomal enzymes in normal and disease states. J. Clin. Invest. 77:1-6.

40. Kelly, R. B. 1985. Pathways of protein secretion in eukaryotes. Science (Wash. DC). 230:25-32. 